\title{
OECD/DAC ENVIRONET(환경과 개발 네트워크)의 기후변화와 개발 논의 동향
}

\author{
임 소 영 KOICA 기후변화·환경1팀 연구관
}

\section{목차}

I. 환경과 개발 네트워크(ENVIRONET)의 개요

1. 역사

2. 구성

3. 협조체제

II. 환경과 개발 네트워크의 주요 활동 내용

1. 기후변화와 개발

2. 환경관리 및 거버넌스의 역량 강화

3. 전략적 환경평가(SEA) 작업반 운영

4. $\mathrm{OECD}$ 녹색성장 전략 수립을 위한 지원

III. 환경과 개발 네트워크 내의 기후변화와 개발

1. 기후변화와 개발협력의 통합

2. 개발협력 내의 기후변화대응을 위한 재원관리

3. 기후변화 완화 및 적응을 위한 원조금액 규모의 측정 및 파악

N. 최근 논의 동향

1. 기후변화의 통합화

2. 기후변화 기금의 운용

3. 기후위험 스크리닝 및 평가 툴(CRSAT)

주제어: 환경과 개발 네트워크(ENVIRONET), 기후변화, 적응, 완화, 통합화 


\section{I. 환경과 개발 네트워크(ENVIRONET)의 개요}

\section{1. 역사}

환경과 개발 네트워크(ENVIRONET, Network on Environment and Development Cooperation)는 DAC 내의 환경과 기후변화에 관한 업무를 전담하는 네트워크로서, 지속가능 개발과 환경의제를 논의하기 위하여 1989년에 설립되었다. 설립 이후 환경과 개발 네트워크는 회원국들의 환경과 개발협력 정책들 간의 조화를 도모하기 위해 다양한 영역에서 활동 중이며, 특히 환경보전 과 지속가능한 개발을 위한 일관성 있는 개발협력 노력에 대한 지침을 수립하고, 개발협력 분야의 환경 이슈 통합에 대한 회원들의 경험과 모범 사례 공유를 위한 정책포럼을 제공하는 활동에 중점 을 두고 있다(외교통상부, 2009).

\section{2. 구성}

환경과 개발 네트워크는 DAC 회원국과 세계은행, UN과 같은 다자기구의 환경 및 기후변화 전문 가들과 함께 수원국, 지역개발은행, $\mathrm{NGO}$, 연구기관을 대표하는 전문가들을 영입하여 활동에 참여 토록 하고 있다. 즉, 기본적으로 $\mathrm{DAC}$ 및 세계은행, $\mathrm{UNDP}$ 와 같은 영구 업저버가 구성되어 있으며, $\mathrm{DAC}$ 비회원국 대표 및 기타 UN 기구, $\mathrm{NGO}$ 및 연구기관의 대표들은 주로 필요에 따라 task team 을 구성하여 활동하고 있다(외교통상부, 2009).

\section{〈2009-2010 기간 동안의 ENVIRONET의 태스크 팀〉}

· 개발-환경 기후변화 합동 태스크 팀 (Joint Development-Environment Climate Change Task Team)

· 자연자원 및 환경관리를 위한 거버넌스 및 역량개발에 관한 개발-환경 합동 태스크 팀 (Joint Development-Environment Task Team on Governance and Capacity Development for Natural Resources and Environmental Management)

- 리우마커의 개선을 위한 환경네트워크-통계작업반 합동 태스크 팀 (Joint ENVIRONET/WPSTAT Task Team on Improving the Rio Markers)

· 전략환경평가에 관한 태스크 팀 (Task Team on Strategic Environmental Assessment) 


\section{3. 협조체제}

환경과 개발 네트워크는 활동의 효과성을 증대하기 위하여 $\mathrm{OECD}$ 환경정책위원회 (Environment Policy Committee, 이하 EPOC) 및 DAC 산하의 통계작업반 (Working Party on Statistics, 이 하 WP-STAT)과 빈곤감소 네트워크 (Network on Poverty Reduction, POVNET) 등 OECD 내 의 여타 위원회 또는 네트워크와의 협조체제를 강화하면서 활동하고 있다.

\section{II. 환경과 개발 네트워크의 주요 활동 내용}

환경과 개발 네트워크의 활동 영역은 크게 다음의 네 분야로 분류된다.

\section{1. 기후변화와 개발}

최근 환경과 개발 네트워크에서 가장 활발하게 논의가 진행되고 있는 주제로서, 특히 기후변화와 개발협력의 통합 ${ }^{1)}$, 개발협력 내의 기후변화대응을 위한 재원관리 및 지원규모의 측정 및 파악에 관 한 활동에 중점을 두고 있다.

\section{2. 환경관리 및 거버넌스의 역량 강화}

$\mathrm{EPOC}$ 와 함께 공동 작업반을 결성하여, 환경과 자연자원의 관리 및 거버넌스와 역량강화를 위하여 지식을 공유하고 관련된 툴, 지침서와 공동의 접근법을 개발하고 있다.

\section{3. 전략적환경평가(SEA) 작업반 운영}

환경문제 해결을 위한 개발협력 수단의 조화를 위해 2004년 환경과 개발 네트워크 내에 SEA 작업 반이 구성되었으며, 이를 통하여 개발협력 내의 SEA에 관한 DAC의 지침서 개발을 시작으로 환경과 개발 네트워크는 지속적으로 $\mathrm{SEA}$ 의 수행을 위한 $\mathrm{OECD}$ 가이드라인 및 참고자료를 발간하고 있다.

1) 국제사회는 국가 또는 국제사회 전반에 걸쳐 지대한 영향을 미치는 몇몇 특정 이슈를 하나의 섹터로만 접근할 경우 간과 될 수 있는 문제가 많고, 또한 역으로 타 분야의 개발 사업이 그 특정 이슈에 미치는 부정적 영향을 제대로 인지할 수 없 기 때문에 이를 포괄적인 틀 안에서 다루어야 한다는 인식하에 특정 이슈의 통합화 또는 주류화를 시도해 왔다 (박명지, 2009). 


\section{OECD 녹색성장 전략 수립을 위한 지원}

환경과 개발 네트워크는 개발도상국의 빈곤층을 고려한 녹색성장을 지원하기 위하여

i) 건전한 자연자원 관리 및 거버넌스의 장려,

ii) 기후변화의 악영향을 최소화하는 개발,

iii) 저탄소 성장의 촉진

을 위해 중점적으로 활동하고 있다.

이들 중 본고는 '기후변화와 개발' 분야에서의 주요 성과 및 논의사항을 중심으로 하는 환경과 개발 네트워크의 활동을 조사, 분석한다.

\section{III. 환경과 개발 네트워크 내의 기후변화와 개발}

가뭄, 홍수, 해수면 상승 등 기후변화의 영향은 식량 부족, 감염성 질병의 증가, 기반시설 및 생계 수단인 자연자원의 손실 등을 초래하며, 이러한 기후변화의 악영향은 특히 빈곤국가의 빈곤층에 더 욱 심각한 타격을 준다. 오늘날 개발의 형태는 기후변화에 대처할 수 있는 역량에 영향을 주며, 아 울러 향후 온실가스 배출의 정도도 좌우하게 된다. 즉, 기후변화는 개도국의 개발목적 달성을 위협 하면서, 역으로 개발정책 형태에 의해 그 정도가 결정될 수 있다. 실제로 기후변화는 빈곤퇴치 및 지속가능개발의 목표 달성을 위협하는 요인으로 지적되고 있으며, 이의 근거는 기후변화와 새천년 개발목표 (MDGs)와의 관계에서 찾아볼 수 있다(임소영, 2010).

이에 환경과 개발 네트워크는 개발협력 정책과 프로그램에 환경과 지속발전 이슈를 통합하고 $\mathrm{OECD}$ 회원국의 환경정책과 개발정책 간의 연관성에 대한 이해를 제고시키기 위해 노력하고 있다 (외교통상부, 2009). 특히 2006년 $\mathrm{OECD}$ 개발장관 및 환경장관 공동각료회의에서 공동목표를 위 한 공동의 행동 틀(Framework for Common Actions around Shared Goals)을 채택하여 개발과 환경에 관한 주요 이슈에 있어 $\mathrm{OECD}$ 회원국들의 공조를 이끌어낼 것을 공약하면서 환경과 개발 네 트워크의 활동은 더욱 활발해질 수 있었다(외교통상부, 2009). 


\section{1. 기후변화와 개발협력의 통합}

기후변화와 개발 간의 높은 상관관계로 인해 기후변화의 주류화 또는 통합화의 필요성이 강조되고 있으며, 이는 국가 개발과정에서 발생되는 기후변화의 영향에 대한 대응 뿐만 아니라 미래에 발생 할 것이 예상되는 영향을 사전에 고려하여 개발효과를 높이고 지속가능한 개발을 도모하기 위한 전 략이라고 정리할 수 있다(박명지, 2009; 임소영, 2010). 특히 기후변화 적응은 개발활동과 밀접하 게 연관되어 있어, 프로젝트 수준과 아울러 국가, 섹터, 지역 수준의 개발 기획과정에 통합될 필요 가 있다.

$\mathrm{OECD}$ 는 수원국 및 공여기관의 개발협력 정책입안자와 실무진들을 대상으로 기후변화를 개발에 통 합하기 위한 정보나 조언을 제공하는 지침서들을 개발해 왔다.

1) 기후변화적응의 개발협력으로의 통합: 정책지침(Integrating Climate Change Adaptation into Development Co-operation: A Policy Guidance (2009a))

동 보고서는 개발 과정에서 기후변화 적응의 통합을 촉진하기 위한 정보 및 조언을 제안하는 정책 지침서로서, 그 동안 $\mathrm{DAC}$ 내에서 가장 중요한 이슈이면서도 산발적으로 이루어져 오던 기후변화 적응의 통합 이슈를 다양한 접근법으로 총망라하였다. 기후변화 적응의 통합을 위한 주된 노력은 개발도상국 자체적으로 이루어져야 하지만, 국제 공여국 및 기관들도 이들을 위한 지원 및 자체 내 의 계획 및 활동에 대한 기후변화 적응의 통합을 위해 중요한 역할을 하게 된다.

본 지침서는 개발 과정에 영향을 미치는 기후변화 및 이와 관련된 기후변화 적응의 통합화의 필요 성에 대한 이해를 증진시키며, 일반적인 기후변화 적응의 통합화 과정2) 뿐 아니라, 국가, 섹터, 프 로젝트, 지역 수준에서의 통합화를 위한 적절한 접근법을 확인하고 있다(그림 $1,2,3$ ).

마지막으로 본 지침서는 공여국들이 개발도상국의 기후변화와 이에 대한 취약성을 줄이기 위해 취 하는 노력을 실제적으로 지원할 수 있는 방안을 제시하고자 하였다. 이를 위해 본 지침서가 사용한 각 수준별 접근방식의 규명, 통합의 시작점(entry point) 확인 등의 내용 전개 방식은 2002년 또 다른 통합에 관한 $\mathrm{OECD}$ 보고서 $(\mathrm{OECD} / \mathrm{DAC}, 2002)$ 의 방식과 닮아 있다.

2) 4단계 접근법 :

i) 현재와 미래의 취약성 및 기후위험의 확인,

ii) 가능한 적응 대책들의 확인,

iii) 적용할 적응 대책들에 대한 평가 및 선택,

iv) 수행된 적응 전략의 성공 여부에 대한 모니터 및 평가 
본 지침서의 핵심은 특정 정책, 계획, 프로젝트가 기후변화에 의한 위험에 취약한 정도와 기후변화 의 위험이 고려된 정도 등을 검토하는 기후렌즈(climate lens)에 있다. 또한 기후변화에 적응하기 위한 도구 및 스크리닝 접근법의 예시를 소개하고 있으며, 전략적환경평가(SEA)를 통한 기후변화 의 통합화 방안도 제시하고 있다.

\section{1) 국가 차원의 통합}

국가 차원의 기후변화 적응 통합은 i) 핵심 이해관계자의 규명 및 참여, ii) 국가 수준의 기후정보에 대한 접근성 개선, iii) 적응 문제에 보다 더 잘 대처할 수 있는 정부조직의 구성 iv), 재난위험감소 를 위한 기존의 국가 메커니즘의 강화, v) 현재 그리고 미래의 기후위험에 대한 각종 규제 및 제도 의 조정, 그리고 vi) 다자·지역기구의 약속과 적응 사이의 연계성 증진 등을 통해 시작된다. 결과 적으로 국가 수준에서 공여국이 기후변화 적응을 통합하기 위해서는 예산지원 메커니즘과 공여국 의 국가지원전략을 통해서 효과적으로 이루어질 수 있다.

〈그림 1〉 국가 수준의 거버넌스 구조 상 개입 가능한 기후변화 적응 고려 요소

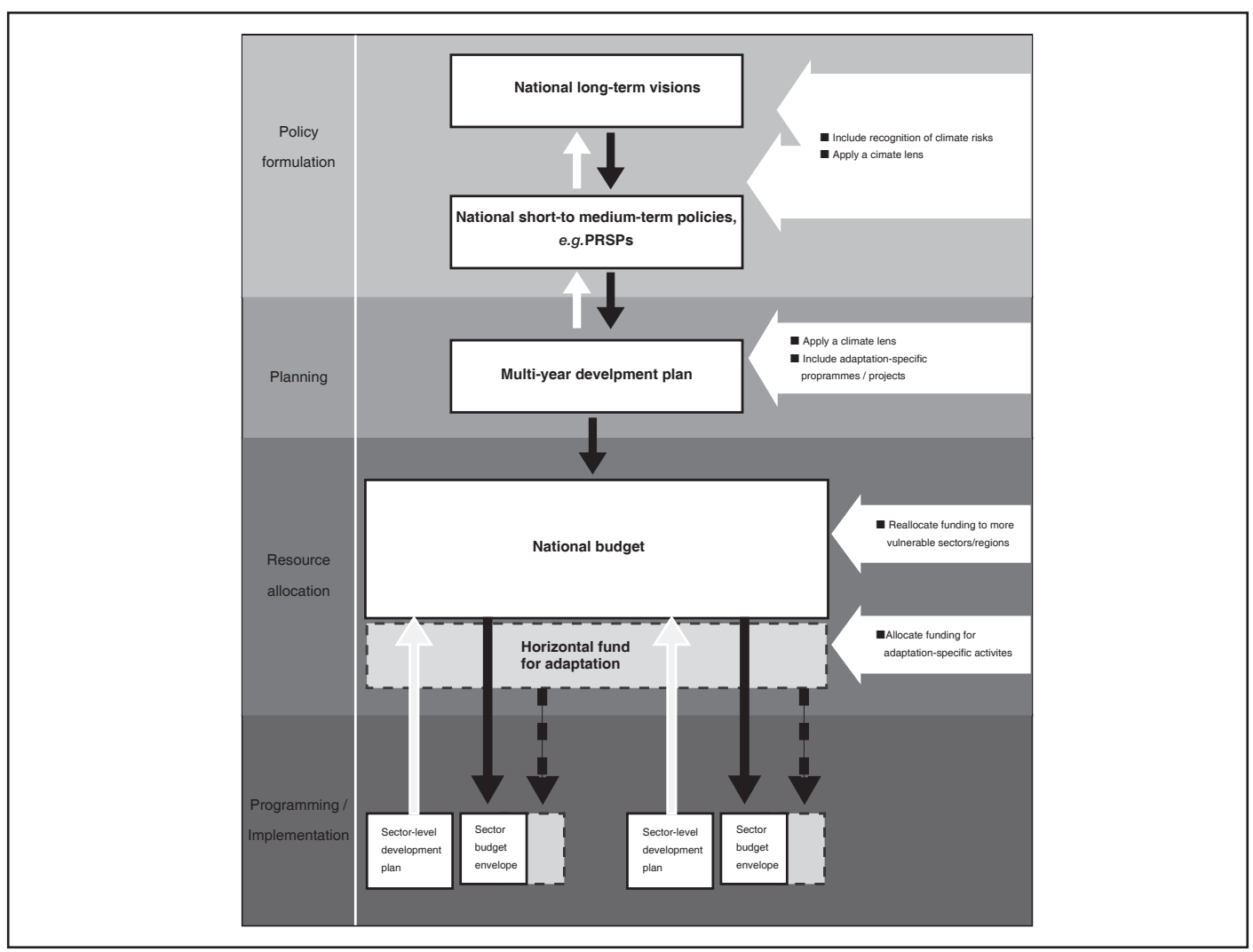

출처 : OECD/DAC(2009a) 


\section{2) 섹터 차원의 통합}

섹터 차원에서 기후변화 적응이 중요하게 고려되어야 하는 섹터로 농업, 산림, 어업, 수자원 관리, 인간 보건, 자연보전, 에너지 등이 도출되었다. 이와 같은 섹터들의 정책입안 단계에서 기후변화 정 보가 충분히 고려되면 적절한 적응행동이 확인되고, 발생할 수 있는 부적응(maladaptation) 활동 을 피할 수 있게 된다. 섹터 수준의 통합을 위해 필요한 주요 활동은 i) 기후변화의 영향이나 취약 성에 관한 섹터별 정보들에 대한 평가 수행, ii) 공여기관 내 특정 사업이나 활동에 대한 기후변화 의 영향력에 대해 섹터부서 기획자 또는 카운터파트들의 인식 제고, iii) 섹터의 규제 또는 의사결정 과정들이 전통적인 기후정보에만 근거하여 마련되었을 경우, 최신의 기후 기준치를 적용하여 갱신, iv) 특정 섹터에 대한 기후변화의 영향을 평가하기 위한 섹터 부처 또는 공여기관 내부의 역량 강 화, v) 적응 활동의 비용 - 편익에 관한 정확한 정보를 수집하여, 다양한 부문의 의사결정자들이 추 후 적응과 관련된 활동에 대해 결정 시 사용하도록 유도 등으로 요약된다.

〈그림 2〉 섹터 수준의 거버넌스 구조 상 개입 가능한 기후변화 적응 고려 요소

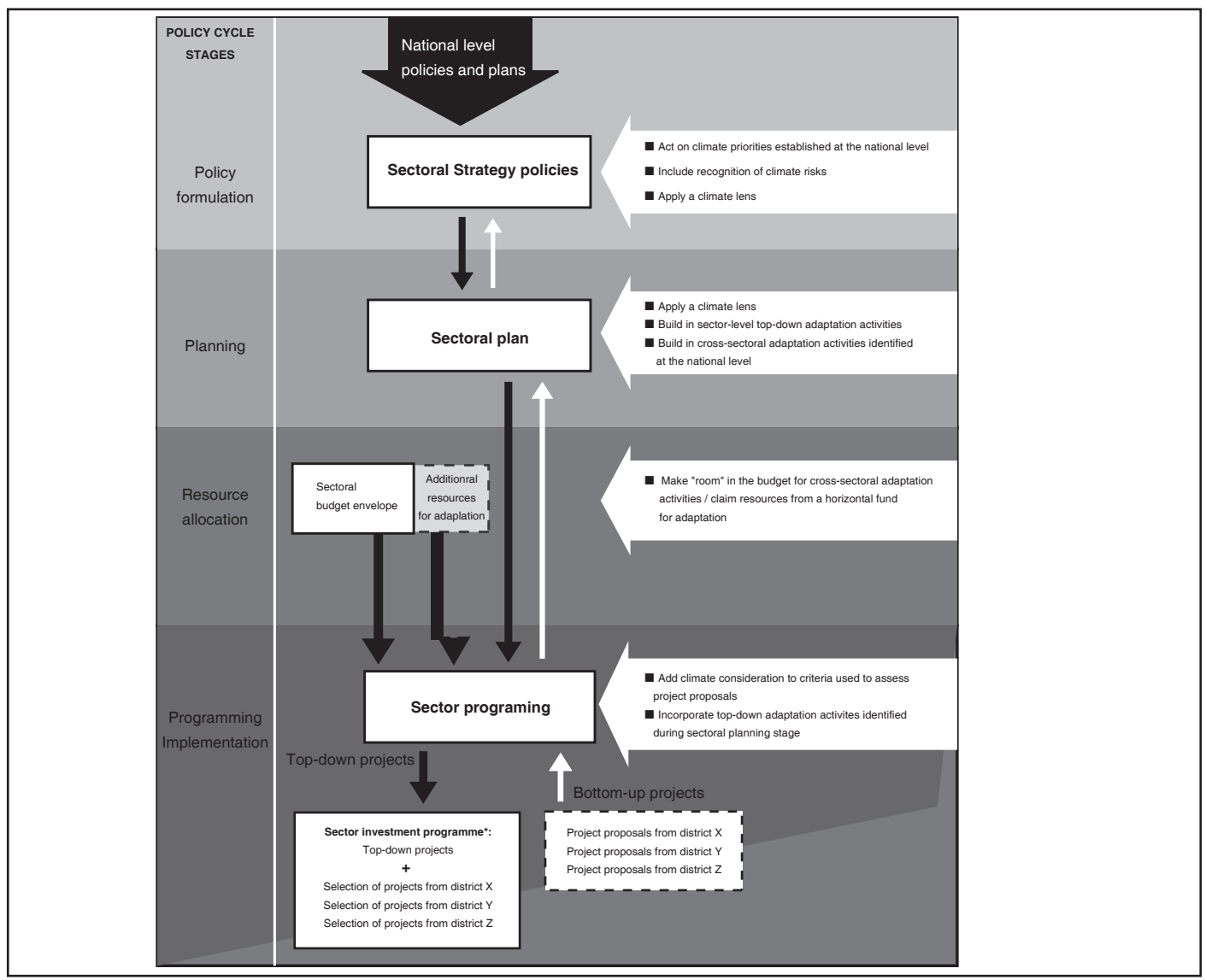

출처 : OECD/DAC(2009a) 


\section{3) 프로젝트 차원의 통합}

정책의 의사결정 단계에서 고려되는 국가 또는 섹터 차원에서의 통합과는 달리 프로젝트 차원의 통 합은 프로젝트 주기 내에서 고려된다. 프로젝트의 주기는 프로젝트 발굴 및 형성, 사전조사, 상세설 계 및 기획, 사업수행, 모니터링 및 평가로 정리될 수 있다.

〈그림 3〉 프로젝트 주기 상 개입 가능한 기후변화 적응 고려 요소

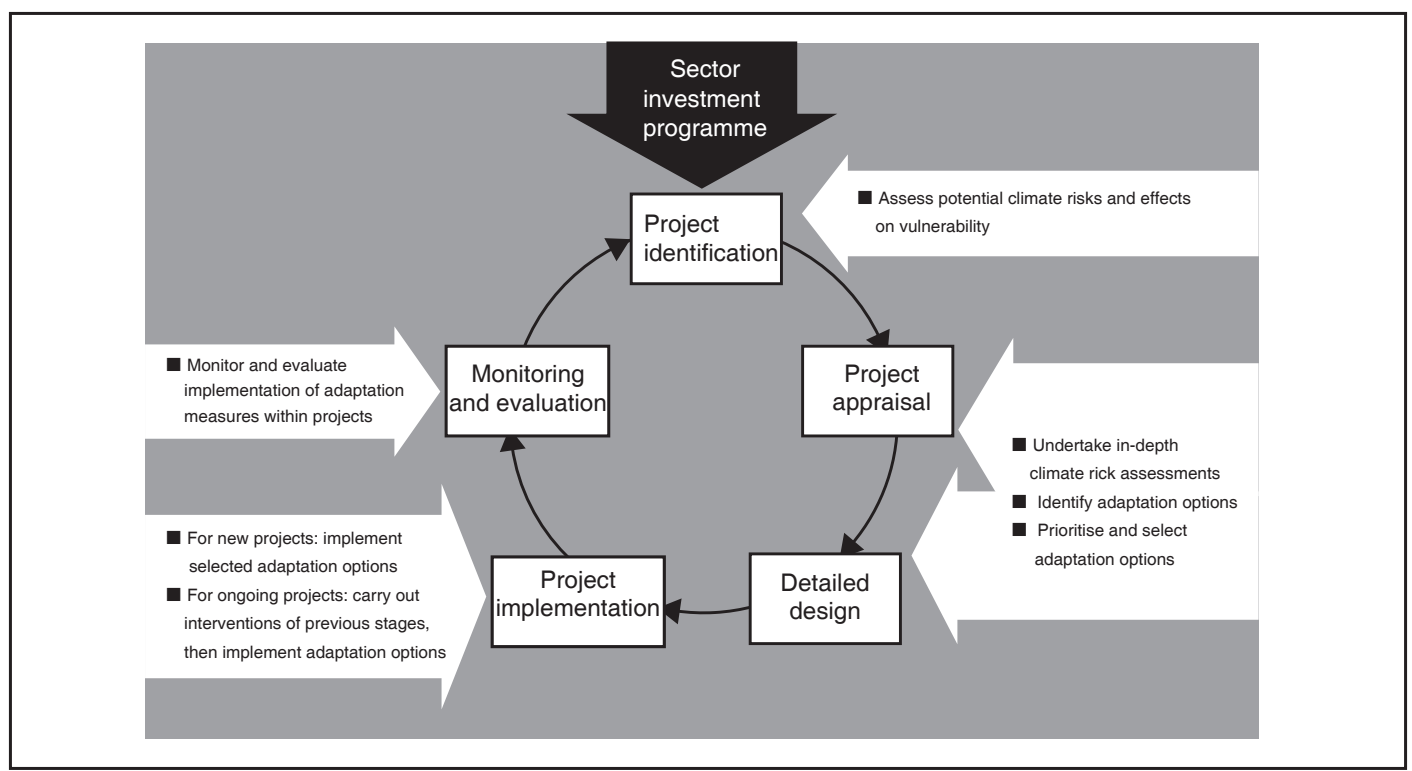

출처 : OECD/DAC(2009a)

\section{2) 기후변화적응의 개발협력활동으로의 통합에 관한 상황점검(Stocktaking of} Progress on Integrating Adaptation to Climate Change into Development Cooperation Activities (2007))

2006년 채택된 기후변화적응의 개발협력 통합에 관한 OECD 선언문 ${ }^{3)}$ 의 이행상황을 확인하기 위하 여, 양자/다자 공여기관과 국제금융기관들의 기후변화 전문가들을 대상으로 하는 설문조사 및 문헌 조사를 통하여 기후변화적응의 통합을 위한 진척 상황을 점검하였다. 구체적으로는 기후변화에 의 해 발생할 수 있는 위험요인들에 대한 인식이 향상되었음을 확인하고, 기후변화 부문의 개도국 지 원을 위하여 국가, 기관 및 국제 다자기구가 생성한 각종 이니셔티브를 조사, 소개하였다. 본 보고

3) Declaration on Integrating Climate Change Adaptation into Development Co-operation (2006년 4월, OECD DAC 및 $\mathrm{EPOC}$ 장관급 회의에서 채택) 
서는 기후변화적응의 통합화를 위한 국제적 노력의 점검을 그 목적으로 하고 있는 만큼, 각 공여국 또는 개발은행들의 통합화를 위한 구체적인 도구 또는 사례를 소개하고 있다는 점이 괄목할 만하 다.

\section{3) 기후변화와 개발의 관계(Bridge over Troubled Waters-Linking Climate}

Change and Development (2005))

환경 및 개발협력 전문가들이 공동으로 집필한 본 보고서는 기후변화 이슈와 국가개발은 각 지역 또는 국가가 지니고 있는 특성에 따라 다양한 형태로 통합될 수 있으므로 하나의 동일한 기준으로 이루어질 수 없음을 인식하면서 6개의 사례연구 (네팔, 탄자니아, 이집트, 방글라데시, 피지, 우루 과이)를 바탕으로 그 해결점을 모색하고자 하였다.

저자들은 기후변화 문제가 국가개발에 통합되기 어려운 이유로 기후변화 문제는 국내정책의 문제 로 국한되지 않고 국제적인 정책대화가 필요한 부문이기 때문이며, 또한 주로 환경과 관련된 부서 에서 다루어지므로 국가 전체의 개발을 위한 전략에 포함되는데 한계가 있다고 지적하였다. 또한 개발정책가들은 이미 성평등, 지속가능개발 등 기후변화 이외에 통합해야 하는 다른 이슈들에 의해 적지 않은 부담을 안고 있으며, 주로 단기간에 수행되는 프로젝트로 장기간에 걸쳐 나타나는 기후 위험의 감소를 기대하기는 어렵다고 판단하였다. 아울러 간혹 기후변화 대책과 국가경제개발이 서 로 상충되는 경우가 있는 점도 통합화를 어렵게 하는 요인으로 지적되었다.

동 보고서는 두 이슈의 통합을 위해서 빈곤감소전략 보고서 (PRSP) 및 여타의 개발전략 안건에 기 후변화 완화 및 적응 문제를 포함할 것을 제안하고, 아울러 기후 관련 정보를 보다 더 적절하고 사 용 가능하도록 만들 것을 권장하고 있다. 또한 기후변화 적응의 비용편익에 관한 정보의 신뢰성을 제고하고, 새로운 계획의 생성보다는 시행에 더 주안점을 둘 것을 강조하고 있다(임소영, 2010).

\section{4) 리우협약의 개발협력으로의 통합(Integrating the Rio Conventions into}

Development Co-operation (2002))

2002년에 발간된 원조 공여기관의 의사결정자 및 개발정책 전문가들을 대상으로 하는 가이드라인 으로서 국제 환경이슈와 지속가능한 개발 및 빈곤전략의 연계성을 규명하고 이를 위한 방향을 제시 하고 있다. 동 가이드라인은 원조의 효과성을 제고하기 위하여 공여기관 뿐 아니라 수원국 관계자 들이 준수하고 고려해야 할 사항도 동시에 명시하고 있다. 기후변화, 생물다양성 유지, 사막화 방지 와 관련된 리우협약들의 이슈가 개발도상국의 빈곤감소 및 개발전략과 어떤 관계가 있으며, 이들을 통합하기 위한 방안은 무엇인지, 아울러 통합에 있어 장애요소가 무엇인지 분석하여 해결방안을 제 
안하였다.

동 지침서는 리우협약을 개발전략에 통합해야 하는 이유로서, i) 개발도상국은 생계를 위해 자연자 원에 대한 의존도가 높고, 환경의 변화에 적응을 하기 위해 필요한 역량이 부족한 개발도상국 빈곤 층의 빈곤감소를 위하여 환경문제 해결은 필수적인 요소이며, ii) 국제환경문제는 환경 섹터 뿐 만 아니라 농업, 에너지, 수송 등 다양한 섹터들에서 해결되어야 한다는 점을 들었다.

통합을 위한 방법으로 동 지침서가 제안한 방법들은 개발도상국의 빈곤감소전략 (PRS) 내에 환 경이슈를 고려하는 방법, 생태계를 기반으로 하는 접근법, 전략환경평가 (SEA) 및 환경영향평가 (EIA)의 적용 등이다(임소영, 2010).

\section{2. 개발협력 내의 기후변화대응을 위한 재원관리}

개발도상국의 기후변화 문제를 해결하기 위해서는 “예측가능하고 지속가능한 적정수준의” 재정 지 원이 필수적이다. 관련된 많은 연구결과들에 따르면, 2030년까지 개발도상국의 온실가스 배출을 억제하고 이미 발생된 기후변화에 적응하기 위해 소요되는 연간 비용이 최소 500 억 불에서 많게는 1,000 억 불대인 것으로 추정되었다. 하지만 지금까지의 기후변화 대응을 위한 지원 금액은 필요한 액수에 상당히 못 미치는 것으로 나타났다.

충분한 재원을 마련하는 문제만큼 중요한 부분이 기후변화 관련 공적기금을 개발도상국에 효과적 으로 지원하여 관리하는 것이며, 환경과 개발 네트워크는 십여 년의 경험을 바탕으로 이를 위한 중 요한 원칙들 ${ }^{4)}$ 을 도출하고 실현하기 위한 지침 및 안내서를 제공하고 있다.

4) 주인의식(ownership), 일치성(alignment), 역량개발(capacity development), 조화(harmonization) 


\section{3. 기후변화 완화 및 적응을 위한 원조금액 규모의 측정 및 파악}

환경과 개발 네트워크는 WP_STAT 및 UNFCCC 사무국과의 공동작업 하에 UNFCCC의 목적인 온실가스 농도의 안정화를 달성하기 위한 사업을 판별하기 위하여 리우마커라라는 정책마커를 개 발, 발전시켜 왔다. 그 결과 DAC 회원국들은 1998-2000년 기간 동안의 리우마커 통계의 검증 및 2004년부터 실시된 3년간의 시범 운영을 통해, 2008년부터 리우마커를 DAC 통계보고에 영구적으 로 포함하는 안에 동의하였다.

그러나 리우마커 내의 기후변화 마커는 온실가스 배출농도의 감축으로 대표되는 기후변화 완화만 을 고려하는 한계점을 드러냄으로써, 특히 최근 개발도상국에서 중요시되는 기후변화 적응 사업을 구분하여 그 지원규모를 파악할 수 있는 새로운 마커의 생성을 요구하였다. 이에 환경과 개발 네트 워크는 2009년 5월부터 WP-STAT과의 합동회의를 개최하여 리우마커의 질적인 개선과 더불어 기 후변화적응 마커의 생성을 논의하여 왔다. 그 결과 $\mathrm{DAC}$ 가 2009년 12 월에 기후변화적응 사업을 판 별할 수 있는 새로운 마커을 승인함으로써 개발도상국의 기후변화 대응을 위한 원조사업의 온전 한 파악이 가능하도록 하는 계기를 마련하였다.

$\mathrm{DAC}$ 통계자료에 따르면, 2007년 DAC 회원국의 양자 ODA 중 총 38억 불이 개발도상국의 온실 가스 배출의 감축을 위하여 지원되었으며, 이는 당해 연도 총 양자 ODA의 약 $4 \%$ 에 해당하는 실 적이다(OECD/DAC, 2009b). 그림 4는 2002-2007년 기간에 기후변화완화 마커로 보고되어 온 $\mathrm{DAC}$ 회원국들의 기후변화 완화를 위한 양자 $\mathrm{ODA}$ 지원 추세를 보여주고 있다. 참고로 여기서 "Principle objective”에 해당하는 사업들은 기후변화완화 마커에 대해 "2"로 표기된 사업들에 해 당되며, 나머지는 “1” 또는 “2”로 표시된 사업들을 모두 합한 실적을 나타내고 있다.

5) 세 가지 리우협약인

i) 기후변화협약(United Nations Framework Convention on Climate Change, UNFCCC),

ii) 생물다양성협약(United Nations Convention on Biological Diversity, UNCBD),

iii) 사막화방지협약(United Nations Convention to Combat Desertification, UNCCD)

의 목적을 달성하기 위한 사업 및 활동을 각각 식별하는 마커. 협약의 목적이 전혀 고려되지 않은 경우 "0", 사업의 중요 한 목적으로 고려된 경우 "1", 주된 목적으로 고려된 경우 "2"로 표기하는 방식 채택.

6) 기후변화적응 마커는 다음의 목적을 달성하기 위한 원조활동을 판별 : "to reduce the vulnerability of human or natural systems to the impacts of climate change and climate-related risks, by maintaining and increasing adaptive capacity and resilience" 


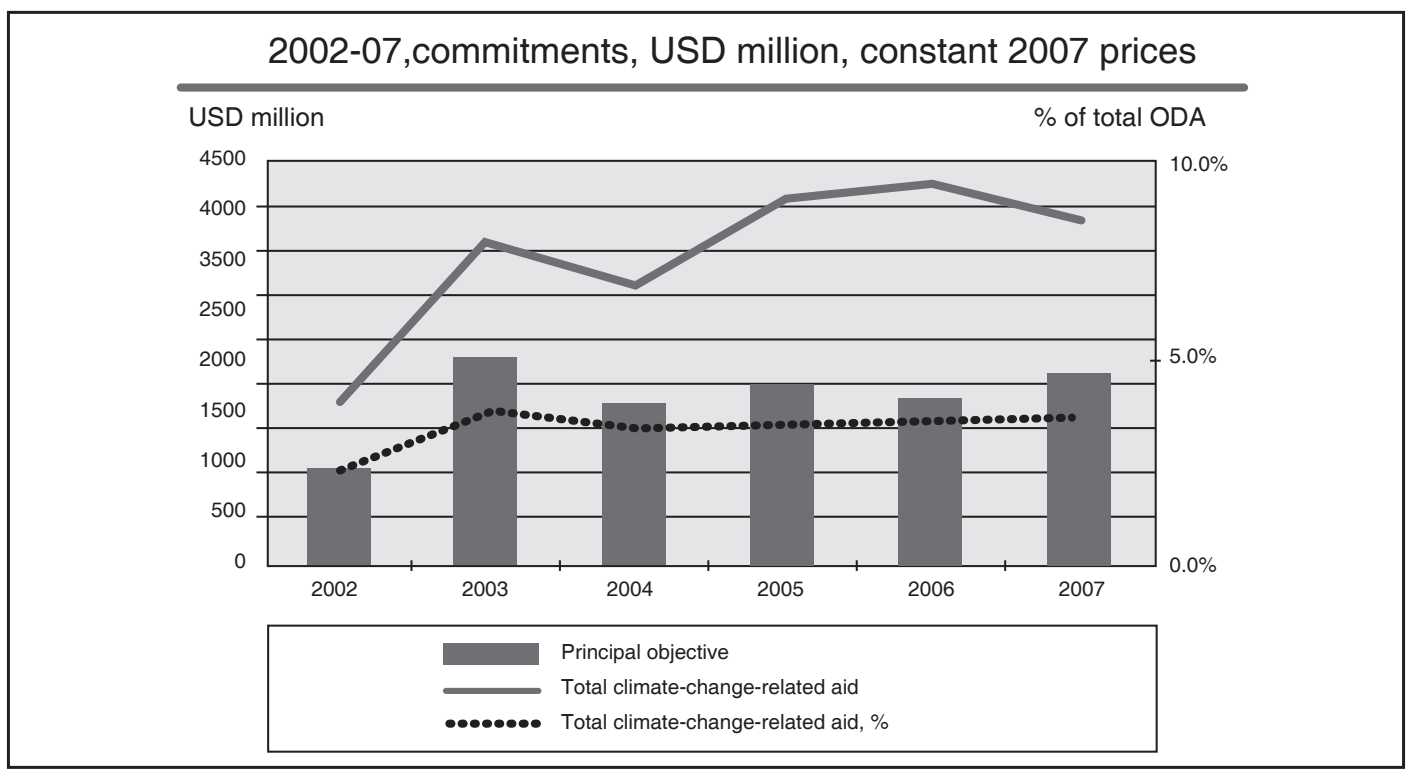

출처 : OECD/DAC(2009b)

\section{IV. 최근 논의 동향}

지난 2010년 2월 23-24일의 이틀에 걸쳐 진행된 회의를 포함하여 환경과 개발 네트워크는 지금까 지 총 10 회의 정례회의를 개최, $\mathrm{DAC}$ 내의 환경문제를 논의하여 왔다. 가장 최근의 정례회의인 지 난 2 월의 10 차 회의 시 논의된 주요 의제로는 환경을 위한 역량개발, SEA에 관한 DAC 지침서, 기 후변화와 개발, 생물다양성과 개발협력, 녹색성장에 관한 $\mathrm{OECD}$ 활동, $\mathrm{DAC}$ 동료검토 내의 환경문 제, 리우협약의 이행을 위한 원조의 통계보고가 선정되어, 각 해당 주제와 관련된 환경과 개발 네트 워크의 그간 활동상황을 점검하고 주요사항을 공유하였다.

\section{1. 기후변화의 통합화}

이들 중 기후변화와 개발에 관한 논의 중 가장 주목을 받고 있는 이슈는 단연코 기후변화 적응을 포 함한 기후변화 문제의 개발협력으로의 통합에 관한 논의라고 할 수 있다. 동 회의에서 각 회원국은 기후변화적응의 통합화를 위한 DAC의 정책지침서(2009) 발간 이후, 이를 따르기 위한 각 국의 경 험을 공유하고 개선방안을 제시하였다. 현재 환경과 개발 네트워크는 동 지침서를 널리 보급하고, 이를 위한 사용자 툴 및 교육과정의 개발에 중점을 두고 있다. 실제로 독일의 GTZ는 동 지침서에 
기반한 교육과정을 제안하였다.

\section{2. 기후변화 기금의 운용}

한편, 회원국 및 공여기관은 코펜하겐 기후변화협약 당사국총회 이후 합의된 기후변화 기금을 효과 적으로 지원하면서, 개발도상국의 동 기금을 운용할 수 있는 능력을 강화하는 방안에 대해서도 논 의하였다. 또한 동 회의에서는 기후변화 대응을 위한 국제사회의 소통과 투명성 제고를 위하여, 관 련 회의에 수원국의 참여를 확대하는 방안도 고려되었다.

\section{3. 기후위험 스크리닝 및 평가 툴 (CRSAT)}

동 회의에서는 "기후위험 스크리닝 및 평가 툴(Climate Risk Screening and Assessment Tools, 이하 CRSAT)"의 사용 경험이 공유되었으며, CRSAT를 환경영향평가(EIA)에 통합하여 사용하는 방안에 대하여 논의되었다. 이러한 CRSAT의 사용에 관한 개선을 위해 사무국은 국제지속가능개 발연구소(IISD)와 공동으로 보다 더 사용자에게 친숙하며 다른 평가 툴과도 연계할 수 있는 방안을 모색 중이다. 


\section{참고 자료}

\section{1. 국내문헌}

박명지 (2009), KOICA 사업의 녹색화 방안, 한국국제협력단, 성남. 외교통상부 (2009), OECD DAC 개황, 외교통상부, 서울

임소영 (2010), 기후변화와 개발도상국 국가개발전략의 통합화 방안, 2010 경제학 공동학술대회 한국환경경제학회 분과, 서울

\section{2. 국외문헌}

Gigli, S. and Agrawala, S. (2007), Stocktaking of Progress on Integrating Adaptation to Climate Change into Development Co-operation Activities, OECD, Paris.

OECD/DAC (2002), Integrating the Rio Conventions into Development Co-operation : The DAC Guideline, OECD, Paris.

OECD/DAC (2005), Bridge over Troubled Waters-Linking Climate Change and Development, OECD, Paris.

OECD/DAC (2009a), Integrating Climate Change Adaptation into Development Cooperation: A Policy Guidance, OECD, Paris.

OECD/DAC (2009b), OECD Development Assistance Committee Tracks Aid in Support of Climate Change Mitigation and Adaptation: Information Note, OECD, Paris.

OECD/DAC (2010a), Room Document No. 6: Report from the Meeting of the Climate Change Task Team, 28-29 January 2010 in Zurich, The 10th Meeting of ENVIRONET, 23-24 February, Paris.

OECD/DAC (2010b), Room Document No. 7: Integrating Climate Change into Development Co-operation: Avenues for Future Work, The 10th Meeting of ENVIRONET, 23-24 February, Paris.

www.oecd.org/dac/environment 